\title{
The effects of Urtica dioica hydroalcoholic extract on the propylthiouracil induced hypothyroidism in rat
}

\author{
Fatemeh Abdolhosseinipoor ${ }^{1}$, Masoud Sadeghi-Dinani ${ }^{2}$, Ali Hosseini-Sharifabad ${ }^{1 * \mathbb{D}}$ \\ ${ }^{1}$ Department of Pharmacology and Toxicology, School of Pharmacy and Pharmaceutical Sciences, Isfahan University of Medical Sciences, Isfahan, Iran \\ ${ }^{2}$ Department of Pharmacognosy, School of Pharmacy and Pharmaceutical Sciences, Isfahan University of Medical Sciences, Isfahan, Iran
}

\section{A R T I C L E IN F O}

Article Type:

Short Communication

\section{Article History:}

Received: 5 January 2018

Accepted: 14 July 2018

\section{Keywords:}

Hypothyroidism Medicinal plants Herbal medicine Propylthiouracil Urtica dioica

\begin{abstract}
A B S T R A C T
Introduction: Hypothyroidism is an important endocrine disorder determined by some depressed symptoms. Urtica dioica (Urticaceae) is a medicinal plant which has been traditionally used for treatment of a wide range of decreased functions of different organs. In the current study, we aimed to evaluate the effect of hydroalcoholic extract of aerial parts of $U$. dioica on thyroid hormones in propylthiouracil (PTU)-induced hypothyroidism in rats.

Methods: Forty-two male Wistar rats were randomly divided into 7 groups including control, PTU, different doses of Urtica dioica hydroalcoholic extract (UDHAE) treated and levothyroxine treated groups. The animals in various groups received water (control group) or water containing $0.1 \%$ W/V PTU and then injected saline (control group) or 25, 50, 100, $150 \mathrm{mg} / \mathrm{kg}$ UDHAE, respectively for 4 weeks. Positive control group was fed levothyroxine $0.5 \mathrm{mg} / \mathrm{kg}$ during the PTU treatment. Then, the blood samples were collected and the levels of thyroxine $\left(\mathrm{T}_{4}\right)$, triiodothyronine $\left(\mathrm{T}_{3}\right)$, free triiodothyronine $\left(\mathrm{FT}_{3}\right.$ ) and thyroid-stimulating hormone (TSH) measured via the Elisa method. Results: The data showed that PTU decreased the blood level of thyroid hormones but increased TSH, significantly. The 50 or $100 \mathrm{mg} / \mathrm{kg}$ doses of UDHAE remarkably increased the blood level of $\mathrm{T}_{3}$ and $\mathrm{FT}_{3}$. The $50 \mathrm{mg} / \mathrm{kg}$ doses of UDHAE increased the blood level of $\mathrm{T}_{4}$. None of the UDHAE doses showed significant change in the TSH levels. 25 and $150 \mathrm{mg} / \mathrm{kg}$ doses of UDHAE did not change the PTU- diminished level of thyroid related hormones.

Conclusion: The findings suggest that $50 \mathrm{mg} / \mathrm{kg}$ dose of UDHAE has stimulatory effect on thyroid gland function and raises plasma $\mathrm{T}_{3} \& \mathrm{~T}_{4} \& \mathrm{FT}_{3}$ levels. UDHAE at the dose of 50 or $100 \mathrm{mg} / \mathrm{kg}$ could enhance blood level of $\mathrm{T}_{3}$ and $\mathrm{FT}_{3}$ perhaps by increase in $\mathrm{T}_{4}$ to $\mathrm{T}_{3}$ transformation. Higher doses of UDHAE could not increase the level of these hormones probably due to the presence of inhibitory materials.
\end{abstract}

Implication for health policy/practice/research/medical education:

The extract of Urtica dioica, in some especial doses reversed the PTU-induced $\mathrm{T}_{3}$ diminution. The results show that it might be effective in hypothyroidism disease.

Please cite this paper as: Abdolhosseinipoor F, Sadeghi-Dinani M, Hosseini-Sharifabad A. The effects of Urtica dioica hydroalcoholic extract on the propylthiouracil induced hypothyroidism in rat. J Herbmed Pharmacol. 2018;7(4):300-305. doi: 10.15171/jhp.2018.45.

\section{Introduction}

Thyroid hormones play an important role in the normal activity of all body tissues. Decrease in the thyroid hormone levels is known as hypothyroidism (1). It can occur because of the deficiency in iodine intake, thyroid gland lesions, autoimmune disorders and impaired activity of pituitary gland $(2,3)$. The untreated hypothyroidism leads to a wide range of abnormalities including loss of energy, fatigue sensation, weight gain, dry skin, depression, behavioral fluctuations, hair loss, hands and face swelling and increased cholesterol (4). For the treatment of hypothyroidism the levels of thyroid hormones should be elevated to normal levels. The common way is the replacement of them with administration of "levothyroxine"(5). Beside levothyroxine, some medications like supplementations or plants are used to help the treatment of hypothyroidism. These components could decrease the peripheral hypothyroidism symptoms or increase the production of related hormones (6-8). Although the well-known hypothyroidism medication, levothyroxine, shows an 
excellent efficacy, it causes different side effects like tachycardia, heat intolerance and tremor (9). So, the use of medicinal plants instead of levothyroxine, or along with it, in treatment of hypothyroidism for better outcome or decrease of its side effects, is attractive for the researchers (10). It has been shown that some plants like Guggulu (Commiphora mukul), Marshmallow (Althaea officinalis L.), Rhodiola rosea, Commiphora Muku, Bacopa monnieri (Water Hyssop) improve the hypothyroidism by involving different mechanisms (1,11-13).

Nettle or Urtica dioica is a famous medicinal plant that grows in the tropical and warm regions from May to September. Nettle consists of a wild range of chemical compounds including sterols, terpenes, coumarins, lignans, ceramids and fatty acids. The flowers, leaves, stem and root of Nettle are used for medicinal purposes (14). For a long time it has been employed for treatment of urological problems like kidney stones and prostatic hyperplasia $(14,15)$. In addition, Nettle has antimicrobial, anti-arthritis and glucose lowering effects (16-19). In traditional medicine, Nettle is known as a plant with hot and dry nature (20). This type of plants is able to increase the metabolism and activity in the body. In other words it possibly can improve the symptoms of hypothyroidism $(21,22)$. In addition it is believed that the sterols and coumarins compounds can change the thyroid hormone $(23,24)$.The present study is going to evaluate the effect of hydroalcoholic extract of aerial parts of $U$. dioica on the level of thyroid hormones in PTU-induced hypothyroid in rats.

\section{Materials and Methods}

Animals

Male Wistar rats weighting 180 to $220 \mathrm{~g}$ were obtained from the animal house in Isfahan School of Pharmacy and Pharmaceutical Sciences, Isfahan, Iran. The animals were housed in polypropylene cages under standard laboratory conditions in a $12 \mathrm{~h}$ light/ $12 \mathrm{~h}$ dark cycles. The rats had free access to tap water and standard pellet diet.

\section{Chemicals}

Propylthiouracil (PTU) was purchased from Iran hormone Pharmaceutical Co, Tehran, Iran. The ELISA assay kits for measurement of serum $\mathrm{T}_{4}, \mathrm{~T}_{3}, \mathrm{FT}_{3}$ and $\mathrm{TSH}$ hormones were purchased from Pishgaman Sanjesh Research Co, Tehran, Iran.

\section{Plant and preparation of extract}

The aerial parts of $U$. dioica were gifted from Booalidaroo Co. (Qom, Iran). The firstly were evaluated and approved by an expert technician and then a voucher specimen of the plant was deposited in the herbarium collection of Isfahan School of Pharmacy.

The maceration method was used for preparation of hydroalcoholic extract. For this purpose, $1176 \mathrm{~g}$ of freshly dried aerial parts of $U$. dioica were crushed and incubated with a mixture of ethanol: water (70:30) solvent at room temperature for four day. The product was filtered and then concentrated under reduced pressure at $50^{\circ} \mathrm{C}$ in a rotary evaporator machine. The obtained extract was freeze-dried and $102.7 \mathrm{~g}$ powder was yielded.

\section{Experimental protocol}

Forty-two male Wistar rats were randomly divided into 7 equal groups. All of them except control group were treated with $0.1 \% \mathrm{~W} / \mathrm{V}$ PTU via the drinking water for 4 weeks. In addition, they were treated according to the following schedule during the PTU exposure period: Control: daily received i.p injection of saline for 4 weeks. $P T U$ : daily received i.p injection of saline for 4 weeks.

UDHAE treated: daily received i.p injection of 25, 50, 100 or $150 \mathrm{mg} / \mathrm{kg}$ doses of UDHAE for 4 weeks.

Levothyroxine: daily received $0.5 \mathrm{mg} / \mathrm{kg}$ levothyroxine by oral gavage for 4 weeks.

At the end of treatments, animals were slightly anesthetized and the blood samples were obtained from the angle eye vein. The plasma was separated and used for the further biochemical evaluations.

Measurement of plasma level of thyroid related hormones The plasma level of $\mathrm{T}_{4}, \mathrm{~T}_{3}, \mathrm{FT}_{3}$ and $\mathrm{TSH}$ were measured via ELISA method using special kits (25). For determination of T4, $25 \mu \mathrm{L}$ and for T3, FT3 and thyroid-stimulating hormone (TSH), $50 \mu \mathrm{L}$ of sample was used. Fifty microliters of assay buffer and $50 \mu \mathrm{L}$ of conjugate solution were added and incubated for 60 minutes in room temperature. Then, the product was rinsed with rinsing solution, 5 times. After that $100 \mu \mathrm{L}$ of chromogenic substrate was added and kept in a dark place for 15 minutes. $100 \mu \mathrm{L}$ of stop solution was added and the plate was shaken by hand for 15-20 seconds. At the end, the absorption of samples was read at $450 \mathrm{~nm}$.

\section{Statistical analysis}

The data were presented as the mean \pm SEM. Statistical analysis was performed by one-way analysis of variance (ANOVA) followed by Tukey post-hoc test using GraghPad Prism software version 4. The values of $P<0.05$ were regarded to be statistically significant.

\section{Results}

Effect of PTU on the thyroid related hormones in rat Administration of $0.1 \%$ PTU via drinking water for 4 weeks, significantly decreased the blood levels of $\mathrm{T}_{4}, \mathrm{~T}_{3}$ and $\mathrm{FT}_{3}$ but increased the level of TSH compare to the control group $(P<0.001)$ (Figure 1$)$.

Effect of Urtica dioica hydroalcoholic extract on the blood level of $\mathrm{T}_{4}$ in rat

While 25, 100 and $150 \mathrm{mg} / \mathrm{kg}$ doses of $U$. dioica 


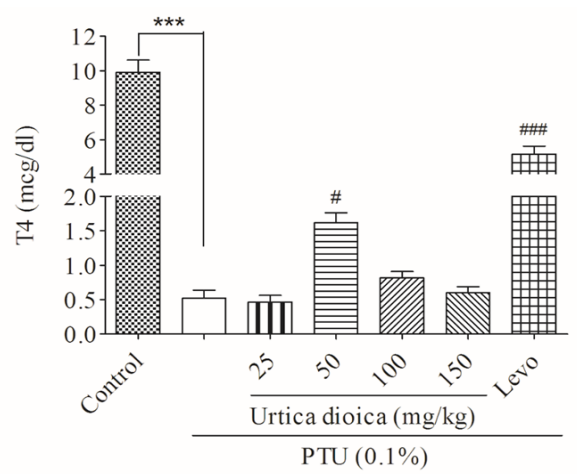

Figure 1. Effect of Urtica dioica extract on blood level of $T_{4}$ in PTU induced hypothyroidism. Values are presented as means \pm SEM (n=6). ${ }^{* * *} P<0.001$ versus saline control group, ${ }^{\# \# \#} P<0.001$ and ${ }^{\#} P<$ 0.05 versus PTU treated group.

hydroalcoholic extract (UDHAE) did not change the level of PTU-induced diminution in $\mathrm{T}_{4}$, its administration at the dose of $50 \mathrm{mg} / \mathrm{kg}$ statistically increased the blood level of $\mathrm{T}_{4}$ compared to the PTU-treated group $(P<0.05$; Figure 1).

Effect of UDHAE on the blood level of $\mathrm{T}_{3}$ in rat Animal treatment with 50 or $100 \mathrm{mg} / \mathrm{kg}$ doses of UDHAE for 4 weeks caused remarkably increase in the blood $\mathrm{T}_{3}$ level compared to the PTU- treated rats $(P<0.001)$. The low $(25 \mathrm{mg} / \mathrm{kg})$ or high $(150 \mathrm{mg} / \mathrm{kg})$ administered doses failed to prevent the PTU-induced decrease in the level of $\mathrm{T}_{3}$ (Figure 2).

Effect of UDHAE on blood level of $\mathrm{FT}_{3}$ in rat A similar pattern of $\mathrm{T}_{3}$ was occurred for the level of $\mathrm{FT}_{3}$. While the 25 or $150 \mathrm{mg} / \mathrm{kg}$ doses of UDHAE didn't show an elevating effect in the level of $\mathrm{FT}_{3}$ compared to the PTUtreated group, 50 or $100 \mathrm{mg} / \mathrm{kg}$ of UDHAE significantly increased the $\mathrm{FT}_{3}$ level which had been decreased by PTU $(P<0.001, P<0.01$, respectively) (Figure 3$)$.

Effect of UDHAE on the blood level of TSH in rat Although the PTU increased the blood level of TSH, none of the studied doses of UDHAE changed the level of TSH compared to the PTU group (Figure 4).

\section{Discussion}

The current study evaluated the effect of hydroalcoholic extract of Urtica dioica aerial part on the serum level of thyroid related hormones in hypothyroidism rats. In the PTU treated animals which received PTU from drinking water for 4 weeks, the serum $\mathrm{T}_{4}, \mathrm{~T}_{3}$ and $\mathrm{FT}_{3}$ levels remarkably decreased and TSH level increased compared to that of control group. PTU is commonly used for the induction of hypothyroidism in the laboratory animals to evaluate the beneficial effects of agents in hypothyroidism treatment $(26,27)$. PTU causes

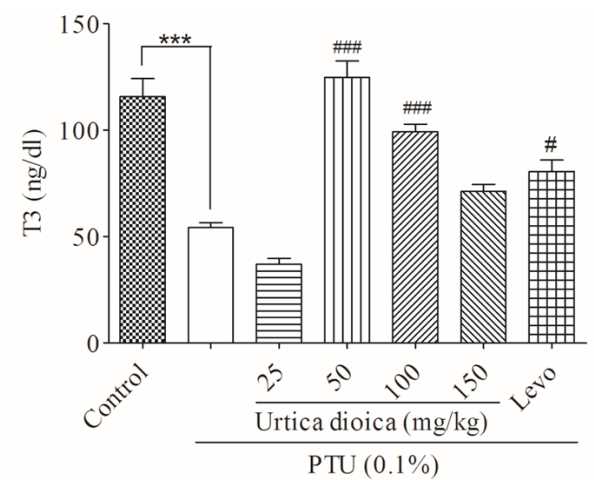

Figure 2. Effect of Urtica dioica extract on blood level of $T_{3}$ in Propylthiouracil (PTU) induced hypothyroidism. Values are presented as means \pm SEM $(n=6) .{ }^{* * *} P<0.001$ versus saline control group, ${ }^{\# \#} P$ $<0.001$ and ${ }^{\#} P<0.05$ versus PTU treated group.

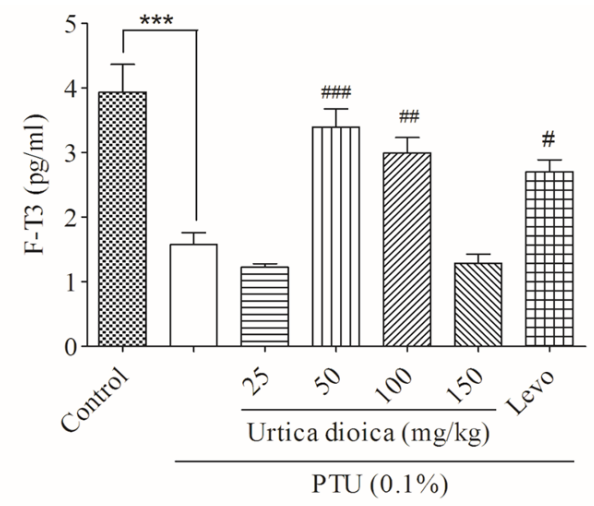

Figure 3. Effect of Urtica dioica extract on blood level of $\mathrm{FT}_{3}$ in Propylthiouracil (PTU) induced hypothyroidism. Values are presented as means + SEM $(n=6) .{ }^{* * *} P<0.001$ versus saline control group, ${ }^{\# \# \# P<}$ 0.001 and ${ }^{\#} P<0.01$ and ${ }^{\#} P<0.05$ versus $P T U$ treated group.

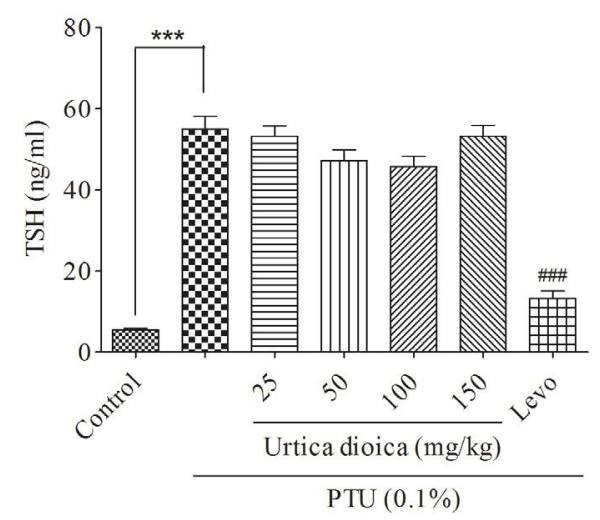

Figure 4. The level of TSH in propylthiouracil (PTU)-treated groups, alone or in combination with different doses of UDHAE and levothyroxine. Values are presented as means \pm SEM $(n=6)$. ${ }^{* * *} P<$ 0.001 versus saline control group, ${ }^{\# \# P} P<0.001$ versus PTU treated group. 
hypothyroidism by inhibition of thyroperoxidase (TPO) which is a key enzyme in production of thyroid hormones (28). In the levothyroxine treated animals, levothyroxine could prevent the decreasing effect of PTU in $\mathrm{T}_{4}, \mathrm{~T}_{3}$ and $\mathrm{FT}_{3}$ levels, also it prevented the increase in TSH level, indicating the animals and the method of measurement were reliable for this study. For the evaluation of UDHAE effect in different doses as well as its dose dependency on hypothyroidism, four increasing doses were chosen. This selection was according to the doses previously used to evaluate other effects of $U$. dioica like its antidiabetic effect $(29,30)$.

UDHAE at the doses of $50 \mathrm{mg} / \mathrm{kg}$ and $100 \mathrm{mg} / \mathrm{kg}$ showed ameliorating effect in the PTU induced disruption of thyroid related hormones. This effect on $\mathrm{T}_{3}$ and $\mathrm{FT}_{3}$ was more significant than that of $\mathrm{T}_{4}$ and TSH levels. On the other word, the levels of $\mathrm{T}_{3}$ and $\mathrm{FT}_{3}$ following administration of 50 and $100 \mathrm{mg} / \mathrm{kg}$ doses of UDHAE came back close to the normal level while $\mathrm{T}_{4}$ level just showed a little increase compared to that of PTU treated animals. The level of TSH in different extract treated groups showed no significant effect compared to the PTU. The preventing effect against the hypothyroidism was most significant after $50 \mathrm{mg} / \mathrm{kg}$ dose of UDHAE. While the low dose of UDHAE did not show any ameliorating effect in the thyroid hormones levels, interestingly this effects were decreased following administration of the studied highest dose. The $150 \mathrm{mg} / \mathrm{kg}$ dose of UDHAE failed to prevent the hypothyroidism induced by PTU. From the findings, it can be deduced that UDHAE in especial doses can encounter to hypothyroidism by increase in transformation of $\mathrm{T}_{4}$ to $\mathrm{T}_{3}$. Because the level of $\mathrm{T}_{3}$ was near to the normal but the $\mathrm{T}_{4}$ level did not significantly change, it can be supposed that if these doses of UDHAE increased the production of $\mathrm{T}_{4}$, all of them transformed to the $\mathrm{T}_{3}$ form. The low dose of UDHAE was not enough to make any change in the thyroid related hormones. Also the studied high doses showed the opposite effect on the thyroid hormones compared to the moderate doses. This event illustrates that the antihypothyroidism effect of UDHAE do not follow a dosedependent manner. The decreasing effect of the higher dose of UDHAE could be due to the presence of inhibitory components. These components overcome other benefit materials in this dose.

There are several phytochemical agents in the UDHAE. They include coumarins, stroles, triterpenes, ceramides and flavonoids (14). It has been previously reported that coumarin derivatives cause increase in the level of thyroid hormones which is in agreement to the current results (23). The specific mechanism of coumarins which increase the thyroid hormones is not well clarified.

In addition, the extract of $U$. dioica possesses a significant antioxidant property $(14,31)$. This effect is resulted from the stimulating effect of extract on the antioxidant enzymes like super oxide dismutase and catalase (32-34). Some of the improving effect of UDHAE against PTU induced hypothyroidism could be related to its antioxidant properties.

Evidence demonstrates that estrol compounds increase the activity of thyroid gland. The stroles could increase the activity of 5'-deiodinase which in turn enhances the conversion of $\mathrm{T}_{4}$ to $\mathrm{T}_{3}(11,24)$. This effect agrees the obtained current results on thyroid hormones in this study.

Interestingly the flavonoid compounds decreased the thyroid hormones by inhibiting the TPO which is the key enzyme in biosynthesis of thyroid hormones $(35,36)$. It is supposed that the effect of flavonoids is dominant in the high doses of UDHAE which leads to the opposing effects on the thyroid hormone levels.

Based on the researches, steroid compounds cause reduction of proteins which transfer Thyroid Hormones in serums (37). Consequently, because of steroids available in $U$. dioica extract, reduction of $\mathrm{T}_{4}, \mathrm{~T}_{3}$ and $\mathrm{FT}_{3}$ hormones in higher doses by reduction of proteins which transfer Thyroid Hormones is also justifiable.

\section{Conclusion}

The findings suggest that $50 \mathrm{mg} / \mathrm{kg}$ dose of UDHAE has stimulatory effect on thyroid gland function and raises plasma $\mathrm{T}_{3}, \mathrm{~T}_{4}$ and $\mathrm{FT}_{3}$ levels. UDHAE at the dose of 50 or $100 \mathrm{mg} / \mathrm{kg}$ could enhance blood level of $\mathrm{T}_{3}$ and $\mathrm{FT}_{3}$ perhaps by increase in $\mathrm{T}_{4}$ to $\mathrm{T}_{3}$ transformation. Higher doses of UDHAE could not increase the level of these hormones probably due to the presence of inhibitory materials. In sum, UDHAE can affect the thyroid action and the effect of this herb on thyroid function depends on the doses which can be effective in treatment of thyroid disorders.

\section{Acknowledgments}

The content of this paper was extracted from the Pharm. D dissertation of Fatemeh Abdolhosseinipoor.

\section{Authors' contributions}

AH: Statistical analysis, data interpretation, manuscript preparation. FA: Data collection, design of the study, literature search, funding collection. MS: design of the study, contributed to conducting the study. All read and confirmed the article ready for publication.

\section{Conflict of interests}

Authors declare no conflict of interests.

\section{Ethical considerations}

Ethical issues (including plagiarism, misconduct, data fabrication, falsification, double publication or submission, redundancy) have been completely observed by the authors. 


\section{Funding/Support}

This research was financially supported by Isfahan University of Medical Sciences, Isfahan, Iran. (Grant No. 3941049).

\section{References}

1. Kar A, Panda S, Bharti S. Relative efficacy of three medicinal plant extracts in the alteration of thyroid hormone concentrations in male mice. J Ethnopharmacol. 2002;81(2):281-5.

2. Ott J, Promberger R, Kober F, Neuhold N, Tea M, Huber JC, et al. Hashimoto's thyroiditis affects symptom load and quality of life unrelated to hypothyroidism: a prospective case-control study in women undergoing thyroidectomy for benign goiter. Thyroid. 2011;21(2):161-7. doi: 10.1089/ thy.2010.0191.

3. Ozturk BT, Kerimoglu H, Dikbas O, Pekel H, Gonen MS. Ocular changes in primary hypothyroidism. BMC Res Notes. 2009;2:266. doi: 10.1186/1756-0500-2-266.

4. Koumourou R. Running on Empty: hypothyroidism, introduction to an underactive thyroid gland. Australia: Cocoon Books; 2004.

5. Mistry D, Atkin S, Atkinson H, Gunasekaran S, Sylvester D, Rigby AS, et al. Predicting thyroxine requirements following total thyroidectomy. Clin Endocrinol (Oxf). 2011;74(3):384-7. doi: 10.1111/j.1365-2265.2010.03940.x.

6. Gartner R, Gasnier BC, Dietrich JW, Krebs B, Angstwurm MW. Selenium supplementation in patients with autoimmune thyroiditis decreases thyroid peroxidase antibodies concentrations. J Clin Endocrinol Metab. 2002;87(4):1687-91. doi: 10.1210/jcem.87.4.8421.

7. Costantini A, Pala MI. Thiamine and Hashimoto's thyroiditis: a report of three cases. J Altern Complement Med. 2014;20(3):208-11. doi: 10.1089/acm.2012.0612.

8. Vahabi Anaraki P, Aminorroaya A, Amini M, Momeni F, Feizi A, Iraj B, et al. Effect of vitamin D deficiency treatment on thyroid function and autoimmunity markers in Hashimoto's thyroiditis: A double-blind randomized placebo-controlled clinical trial. J Res Med Sci. 2017;22:103. doi: 10.4103/jrms.JRMS_1048_16.

9. Levothyroxine Side Effects. drugs.com website. 2017 [cited 2018 April 10]. Available from: https://www.drugs.com/sfx/ levothyroxine-side-effects.html.

10. Ernst E. The efficacy of herbal medicine--an overview. Fundam Clin Pharmacol. 2005;19(4):405-9. doi: 10.1111/j.1472-8206.2005.00335.x.

11. Panda S, Kar A. Guggulu (Commiphora mukul) potentially ameliorates hypothyroidism in female mice. Phytother Res. 2005;19(1):78-80. doi: 10.1002/ptr.1602.

12. Roshangar F, Modaresi M, Toghyani M. Effect of marshmallow's root extract on thyroid hormones in Broilers Res J Appl Sci Eng Technol. 2014;7(1):161-4. doi: 10.19026/rjaset.7.234.

13. Lima STC, Merrigan TL, Rodrigues ED. Thyroid and parathyroid diseases-new insights into some old and some new issues. Croatia: InTech; 2012:221-8.

14. WHO. Radix Urticae. WHO Monographs on Selected Medicinal Plants. Geneva: World Health Organization; 2003:327-41.
15. Moradi HR, Erfani Majd N, Esmaeilzadeh S, Fatemi Tabatabaei SR. The histological and histometrical effects of Urtica dioica extract on rat's prostate hyperplasia. Vet Res Forum. 2015;6(1):23-9.

16. Motamedi H, Seyyednejad SM, Bakhtiari A, Vafaei M. Introducing Urtica dioica, a native plant of Khuzestan, as an antibacterial medicinal plant. Jundishapur J Nat Pharm Prod. 2014;9(4):e15904.

17. Roman Ramos R, Alarcon-Aguilar F, Lara-Lemus A, FloresSaenz JL. Hypoglycemic effect of plants used in Mexico as antidiabetics. Arch Med Res. 1992;23(1):59-64.

18. Bnouham M, Merhfour FZ, Ziyyat A, Mekhfi H, Aziz M, Legssyer A. Antihyperglycemic activity of the aqueous extract of Urtica dioica. Fitoterapia. 2003;74(7-8):677-81.

19. Obertreis B, Giller K, Teucher T, Behnke B, Schmitz H. [Anti-inflammatory effect of Urtica dioica folia extract in comparison to caffeic malic acid]. Arzneimittelforschung. 1996;46(1):52-6.

20. Hughes RE, Ellery P, Harry T, Jenkins V, Jones E. The dietary potential of the common nettle. J Sci Food Agric. 1980;31(12):1279-86.

21. Parvinroo S, Zahediasl S, Sabetkasaei M, Kamalinejad M, Naghibi F. The effects of selected hot and cold temperament herbs based on Iranian traditional medicine on some metabolic parameters in normal rats. Iran J Pharm Res. 2014;13(Suppl):177-84.

22. Parvinroo S, Naghibi F, Zahediasl S, Kamalinejad M, Sabetkasaei M. The effects of seeds with hot and cold temperaments on serum thyroid hormones, corticosterone and urine vanillylmandelic acid concentrations of healthy rats. J Ethnopharmacol. 2014;156:216-21. doi: 10.1016/j. jep.2014.08.026.

23. Qin LP, Zhang HM, Zhang WD. [Effect of osthol and total coumarins of Fructus cnidii on thyroid hormone and thyrotropic hormone in kidney-yang deficiency rats]. Zhongguo Zhong Xi Yi Jie He Za Zhi. 1996;16(9):552-3.

24. Awaisheh SS, Khalifeh MS, Al-Ruwaili MA, Khalil OM, Al-Ameri OH, Al-Groom R. Effect of supplementation of probiotics and phytosterols alone or in combination on serum and hepatic lipid profiles and thyroid hormones of hypercholesterolemic rats. J Dairy Sci. 2013;96(1):9-15. doi: 10.3168/jds.2012-5442.

25. Shamsian AA, Ghazvini K, Sokhtanloo M, Moghaddam MS, Vakili R. Which quantitative method in determination of the thyroid hormone levels is more consistent with the clinical symptoms of the thyroid disorders? Comp Clin Path. 2016;25(1):101-6. doi: 10.1007/s00580-015-2148-2.

26. Mirazi N, Abdolmaleki N, Mahmoodi M. Study of salvia officinalis hydroethanolic extract on serum thyroid hormone levels in hypothyroid male rat. Avicenna J Clin Med. 2013;19(4):27-35.

27. Tousson E, Ali EM, Ibrahim W, Mansour MA. Proliferating cell nuclear antigen as a molecular biomarker for spermatogenesis in PTU-induced hypothyroidism of rats. Reprod Sci. 2011;18(7):679-86. doi: $10.1177 / 1933719110395401$.

28. Bertram GK. Thyroid and antithyroid drugs. In: Shafiei A, ed. Basic and Clinical Pharmacology. Thehran: Andishe Rafih; 2012:883.

29. Kavalali G, Tuncel H, Goksel S, Hatemi HH. Hypoglycemic 
activity of Urtica pilulifera in streptozotocin-diabetic rats. J Ethnopharmacol. 2003;84(2-3):241-5.

30. Ahangarpour A, Mohammadian M, Dianat M. Antidiabetic effect of hydroalcholic urticadioica leaf extract in male rats with fructose-induced insulin resistance. Iran J Med Sci. 2012;37(3):181-6.

31. Zengin $\mathrm{H}$, Baysal AH. Antibacterial and antioxidant activity of essential oil terpenes against pathogenic and spoilage-forming bacteria and cell structure-activity relationships evaluated by SEM microscopy. Molecules. 2014;19(11):17773-98. doi: 10.3390/molecules191117773.

32. Houshmand F, Faghihi M, Zahediasl S. The role of oxytocin on cardiac ischemia-reperfusion-induced oxidative stress in rats. Iran J Endocrinol Metab. 2011;12(6):633-40.

33. Tahiliani P, Kar A. Role of Moringa oleifera leaf extract in the regulation of thyroid hormone status in adult male and female rats. Pharmacol Res. 2000;41(3):319-23. doi: 10.1006/phrs.1999.0587.

34. Tahiliani P, Kar A. Achyranthes aspera elevates thyroid hormone levels and decreases hepatic lipid peroxidation in male rats. J Ethnopharmacol. 2000;71(3):527-32.

35. Ferreira AC, Neto JC, da Silva AC, Kuster RM, Carvalho DP. Inhibition of thyroid peroxidase by Myrcia uniflora flavonoids. Chem Res Toxicol. 2006;19(3):351-5. doi: 10.1021/tx0501684.

36. Ferreira AC, Lisboa PC, Oliveira KJ, Lima LP, Barros IA, Carvalho DP. Inhibition of thyroid type 1 deiodinase activity by flavonoids. Food Chem Toxicol. 2002;40(7):9137.

37. Cooper DS, Klibanski A, Ridgway EC. Dopaminergic modulation of TSH and its subunits: in vivo and in vitro studies. Clin Endocrinol (Oxf). 1983;18(3):265-75. 